\title{
Intranasal Insulin as a Treatment for Alzheimer's Disease: A Review of Basic Research and Clinical Evidence
}

\author{
Jessica Freiherr • Manfred Hallschmid • William H. Frey II • \\ Yvonne F. Brünner · Colin D. Chapman · Christian Hölscher • \\ Suzanne Craft · Fernanda G. De Felice $\cdot$ Christian Benedict
}

Published online: 30 May 2013

(c) The Author(s) 2013. This article is published with open access at Springerlink.com

\begin{abstract}
Research in animals and humans has associated Alzheimer's disease (AD) with decreased cerebrospinal fluid levels of insulin in combination with decreased insulin sensitivity (insulin resistance) in the brain. This phenomenon is accompanied by attenuated receptor expression of insulin and insulin-like growth factor, enhanced serine phosphorylation of insulin receptor substrate-1, and impaired transport of insulin across the bloodbrain barrier. Moreover, clinical trials have demonstrated that intranasal insulin improves both memory performance and metabolic integrity of the brain in patients suffering from $\mathrm{AD}$ or its prodrome, mild cognitive impairment. These results, in conjunction with the finding that insulin mitigates hippocampal synapse vulnerability to beta amyloid, a peptide thought to be causative in the development of $\mathrm{AD}$, provide a strong rationale for hypothesizing that pharmacological strategies bolstering brain insulin signaling, such as intranasal administration of insulin, could have significant potential in the treatment and prevention of $\mathrm{AD}$.
\end{abstract}

J. Freiherr $(\varangle)$ · Y. F. Brünner

Department of Diagnostic and Interventional Neuroradiology,

RWTH Aachen University, Pauwelsstr. 30, 52074 Aachen,

Germany

e-mail: jfreiherr@ukaachen.de

M. Hallschmid

Department of Medical Psychology and Behavioral

Neurobiology, University of Tübingen, Tübingen, Germany

M. Hallschmid

Institute for Diabetes Research and Metabolic Diseases of the Helmholtz Centre Munich at the University of Tübingen (Paul Langerhans Institute Tübingen), Tübingen, Germany

W. H. Frey II

Alzheimer's Research Center of the HealthPartner's Center for Memory and Aging, St. Paul, MN, USA
With this view in mind, the review at hand will present molecular mechanisms potentially underlying the memoryenhancing and neuroprotective effects of intranasal insulin. Then, we will discuss the results of intranasal insulin studies that have demonstrated that enhancing brain insulin signaling improves memory and learning processes in both cognitively healthy and impaired humans. Finally, we will provide an overview of neuroimaging studies indicating that disturbances in insulin metabolism-such as insulin resistance in obesity, type 2 diabetes and $\mathrm{AD}$ - and altered brain responses to insulin are linked to decreased cerebral volume and especially to hippocampal atrophy.

\section{Introduction}

Alzheimer's disease (AD) is a pathophysiological process leading to, but starting long before dementia emerges [1]. $\mathrm{AD}$ affected 35.6 million people worldwide in the year

C. D. Chapman · C. Benedict $(\square)$

Department of Neuroscience, Uppsala University,

Uppsala, Sweden

e-mail: christian.benedict@neuro.uu.se

C. Hölscher

Biomedical and Life Sciences, Lancaster University,

Lancaster, UK

S. Craft

J. Paul Sticht Center on Aging, Department of Medicine,

Wake Forest University School of Medicine, Winston-Salem,

NC, USA

F. G. De Felice

Institute of Biochemistry, Federal University of Rio de Janeiro, Rio de Janeiro, Brazil 
2012 [2]. Due to aging of the human population in developed and developing societies, it is expected that this number will double by the year 2030 and more than triple by 2050 [3]. In the US alone, the cost of caring for individuals with $\mathrm{AD}$ is expected to rise from 200 billion dollars in 2012 to 1.1 trillion in 2050 [4]. Thus, AD and related forms of dementia have become one of the most severe socioeconomic and medical burdens impacting modern society [5]. Even small advances in therapeutic strategies could lead to a delay in the onset and progression of $\mathrm{AD}$ and would significantly reduce this burden.

Alterations in brain insulin metabolism have been suggested as one pathophysiological factor underlying this neurodegenerative disorder [6-8]. In line with this hypothesis, AD patients show reduced brain insulin receptor sensitivity $[9,10]$, hypophosphorylation of the insulin receptor and downstream second messengers such as the insulin receptor substrate-1 $[10,11]$ and attenuated insulin and insulin-like growth factor receptor expression [11]. Furthermore, reduced cerebrospinal fluid (CSF) insulin levels have been observed in moderate and severe cases of $\mathrm{AD}$ [12]; however, this research is not conclusive. Other studies have demonstrated either normal [13] or increased CSF insulin levels in AD patients [14]. Moreover, in the only existing study measuring CSF insulin levels in $\mathrm{AD}$ brains that explicitly used age-matched healthy control brains, normal levels of the hormone were detected [15]. Similar findings have been reported for insulin and insulin-like growth factor receptor expression-evidence for attenuated levels [11], but also for normal or increased levels exists [10, 15]. Figure 1 provides an overview on the putative role of insulin in $\mathrm{AD}$ pathology.

As enhanced brain insulin signaling improves memory processes in cognitively healthy humans [16-18] and possesses neuroprotective properties $[19,20]$, increasing brain insulin concentrations in $\mathrm{AD}$ patients could be a promising approach to prevent or slow the progression of this devastating disease. Thus, it is not surprising that intranasal administration of insulin in $\mathrm{AD}$ patients enabling insulin to directly access the brain [21, 22] was recently selected by the National Institute of Health (NIH) as one of two therapeutic strategies receiving substantial funding as part of the National Alzheimer's Plan in the US. This plan is a federal initiative to find an effective way to prevent or treat AD by 2025 [23].

In this review we will explore the underlying neural network and possible molecular mechanisms that mediate the protective effects of insulin in the human brain. Also, we aim to provide an overview of the concept and current findings regarding the use of intranasal insulin to improve memory function in healthy and cognitively impaired humans.

\section{Role of Insulin in Normal Brain Function}

In healthy participants, intranasal insulin administration over the course of 8 weeks improved performance on a declarative memory task (delayed recall) based on a word list that had to be remembered acutely and 1 week later [16]. This enhancing effect on declarative memory, a hippocampus-dependent function [24], was amplified when insulin aspart, a fast-acting insulin analog, was used [25]. More recent studies have provided evidence that even a single acute dose of insulin (160 IU) enhances hippocampus-dependent memory processes, as measured by both spatial and working memory tasks $[18,26]$. Furthermore, verbal working memory, a capacity that relies on activation of the frontal cortex [27], is improved after a single intranasal application of insulin [18].

\section{Intranasal Insulin Improves Memory Function in Cognitively Impaired Humans}

A single dose of intranasal insulin acutely improved memory in memory-impaired older adults with AD or mild cognitive impairment (MCI) and also improved memory and cognitive function with multiple treatments of patients with AD or MCI [28]. Insulin was effective in improving performance on a verbal memory test in a group of $\mathrm{AD}$ and MCI patients; however, within this group subjects carrying the APOE 44 allele, a strong genetic predictor for AD, showed poorer recall following insulin administration compared to patients that do not posses this allele and healthy controls [28]. Further work from the same group suggests a differential dose-response curve to intranasally applied insulin, such that word and story recall was enhanced by a relatively low dose of insulin in patients that do not posses the APOE $\varepsilon 4$ allele while APOE $\varepsilon 4$ patients demonstrated a relative decline in memory [29]. Additional research indicated that attention and functional status (e.g., orientation, judgment, social interactions, home activities, personal care, speech/language) of this patient group was enhanced by insulin [30].

In the first pilot clinical trial on the use of intranasal insulin therapy in $64 \mathrm{MCI}$ and $40 \mathrm{AD}$ patients, participants received either placebo, $20 \mathrm{IU}$ of insulin, or $40 \mathrm{IU}$ of insulin administered with a nasal spray over the course of 4 months. The main outcome measures were delayed story recall, Dementia Severity Rating Scale, Alzheimer Disease's Assessment Scale-cognitive subscale and Alzheimer's Disease Cooperative Study-activities of daily living scale. Subsets of participants further underwent lumbar puncture and a positron emission tomography (PET) study before and after treatment. The between-subject comparison showed that intranasal insulin improved delayed 
Fig. 1 Overview of the role of insulin and insulin sensitivity in the pathology of Alzheimer's disease

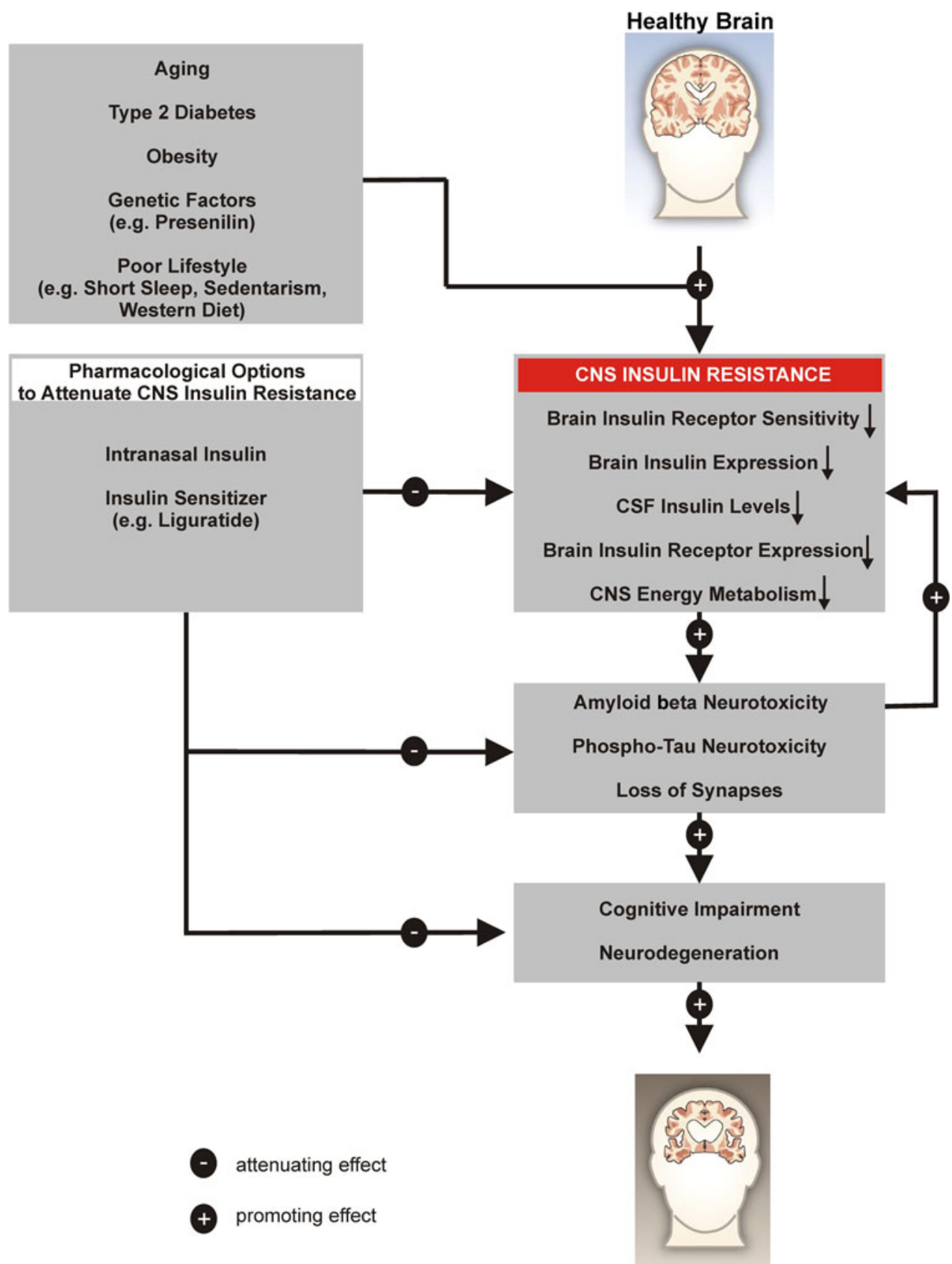

Alzheimer's disease memory and cognitive function, and, importantly, also preserved the functional ability of the patients as estimated by caregiver ratings, suggesting that the improvements were clinically relevant. Based on PET findings, the authors also provided direct evidence for a higher ${ }^{18} \mathrm{~F}$ fluorodeoxyglucose uptake in the parietotemporal, frontal, precuneus and cuneus regions of the CNS following intranasal insulin compared to placebo administration, linking the enhancement in functioning to processes in those brain areas [31]. As indicated by Schiöth et al. [32], this clinical trial employed a relatively low sample size, the treatment period was comparatively short, and, in absolute terms, the improvements were moderate. Nevertheless, the improvements in episodic memory were still present 2 months after cessation of treatment.

A meta-analysis investigating structural brain changes in patients with MCI revealed convergent gray matter atrophy in the bilateral amygdala and hippocampus, extending to the left medial temporal pole, thalamus and bilateral precuneus [33]. Significant reduction of gray matter volume in perirhinal and hippocampal regions and a functional decline in inferior parietal lobules and precuneus has also been established in patients during the conversion from amnestic MCI to AD, as well as patients with early AD [34, 
35]. Taken together, these imaging studies reveal brain atrophy in the hippocampal region, which seems to be the most consistent structural marker of the associated cognitive deterioration and a strong predictor of $\mathrm{AD}$.

In conclusion, the present research is promising because small but consistent improvements of cognitive memory processes induced by insulin have been discovered [36]; however, further clinical trials are needed to assess the clinical relevance of intranasal insulin in the treatment of cognitive disorders.

\section{Disturbances in Insulin Signaling and Glucose Metabolism are Linked to Altered Brain Responses to Insulin}

Impaired insulin sensitivity of the brain and in the periphery of the human body, so-called insulin resistance, is associated with cognitive decline and smaller total brain size [37]. Further, in the insulin-resistant state reduced spontaneous (task-independent) cortical activity has been observed as reflected by decreased theta band activity, a low-frequency EEG component of which is positively related to memory performance [38]. Supporting this view, biochemical analysis of brains of $\mathrm{AD}$ patients revealed central nervous system (CNS) insulin desensitization, which was correlated with the magnitude of cognitive impairments [10, 39]. Disturbances in glucose and energy metabolism and brain insulin signaling are therefore considered a pathological hallmark of $\mathrm{AD}[7,40]$.

In a recent ${ }^{18} \mathrm{~F}$ PET study, insulin resistance was also associated with a pattern of reduced cerebral glucose metabolism in frontal, temporo-parietal and cingulate regions in cognitively intact adults with prediabetes or type 2 diabetes [41]. Bearing in mind that such patterns of hypometabolism have likewise been observed in patients with MCI and AD [42, 43] and that diabetes is a risk factor for $\mathrm{AD}$ [44], screening for insulin resistance may provide a relatively low-cost, non-invasive means for identifying adults at risk to develop the disease.

In a voxel-based morphometric (VBM) study in a large population of healthy elderly subjects (at the age of 75 years), Benedict and colleagues [37] were able to show that the HOMA-IR score, a measure of peripheral insulin resistance, was negatively correlated with verbal fluency performance, total brain size and regional gray matter volume in bilateral areas of the middle and superior temporal gyri, i.e., typical speech-processing areas. Willette et al. [45] confirmed this finding for middle-aged healthy subjects (at the age of 58 years). Further results from a structural imaging study in healthy participants point toward an inverse correlation of peripheral insulin resistance with total cerebral volume, but also with executive functions, verbal and visuospatial memory [46]. The HOMA-IR score of patients at risk for $\mathrm{AD}$ was negatively associated with right and total hippocampal volume as well as overall cognitive performance, and verbal and nonverbal memory tests [47]; however, unlike in the previously mentioned study involving MCI patients, this correlation was not influenced by the presence of the APOE $\varepsilon 4$ allele. In conclusion, these studies shed light on anatomical correlates of healthy and cognitively impaired individuals and provide evidence for diminished total brain and hippocampal volume with higher insulin resistance rates.

Using resting-state imaging methods the activity of the brain in the absence of an external stimulus or task is assessed. Here, spontaneous fluctuations that are useful to explore the brain's functional organization are of interest. The most important resting-state network is the defaultmode network (DMN), which is activated when we are awake and at rest and is deactivated during goal-oriented behavior. The DMN is an interconnected system of medial prefrontal, medial temporal, posterior cingulate, medial, lateral and inferior parietal cortical areas as well as the ventral precuneus. The resting-state activity and also the degree of structural and functional connectivity of the resting-state network is a biomarker for cognitive function and aging. In women at risk for $\mathrm{AD}$, elevated plasma insulin levels have been associated with a decrease of connectivity between the DMN areas prefrontal cortex and hippocampus, pointing toward an involvement of the connectivity of these brain areas in AD pathology [48].

It has further been revealed in magnetoencephalography (MEG) studies in cognitively healthy subjects that intranasal insulin modifies the brain network during the resting state by changing the characteristic path length in the theta band [49]. The theta band or theta rhythm is a frequency component that tends to appear during rest. The authors considered this phenomenon an increase in communication efficiency, particularly between brain areas involved in satiation and homeostatic control of eating behavior caused by the rise in CSF insulin level. In addition, insulin modulated intrinsic cortical activity in hypothalamic and orbitofrontal cortex areas [50], two brain areas involved in the modification of reward during food consumption. Whereas intranasally applied insulin had no effects on basal cerebral blood flow (CBF) or task-induced CBF after visual stimulation [51], a decrease of the blood oxygen level-dependent (BOLD) response after visual stimulation with food pictures was found in several areas of the frontotemporal network [52]. The authors of the latter studies primarily attribute their findings to the importance of insulin signaling during processes related to food consumption and the location of food sources. However, these findings do not allow conclusions regarding the effect of intranasal insulin on the connectivity strength of brain 
components affected in the early stages of $\mathrm{AD}$, such as the hippocampus.

Since the homeostatic system heavily depends upon the sense of smell and, interestingly, the brain regions first affected by $\mathrm{AD}$ are those involved in the sense of smell (e.g., olfactory bulb, entorhinal cortex, hippocampus) [53], it seems reasonable that distortions in olfactory performance are experienced very early in the progression of the pathology [54]. This hypothesis is further supported by research in the rat model proving that ablation of the olfactory bulbs leads to a deficiency in spatial memory and higher levels of beta amyloid in the hippocampal areas [55]. Olfactory performance scores are hence considered behavioral markers for an early diagnosis of AD [56] or other neurodegenerative disorders. As olfactory information enters the human cortical areas without a thalamic relay, they have direct access to brain areas responsible for emotional processing (amygdala) and memory formation (hippocampus). Consequently, odors are potent cues for memory consolidation. Since the brain regions involved in olfactory and memory processes both contain high amounts of insulin receptors [57, 58], future studies should elaborate whether the memory-enhancing effects of insulin could be potentiated by presenting associated odor cues.

\section{Molecular Mechanisms of the Protective Actions of Insulin in the Brain}

Although defective brain insulin signaling is increasingly considered an important feature of AD pathology, the biological mechanisms of brain insulin resistance in $\mathrm{AD}$ have just recently started to be unraveled. Initial molecular clues came from studies demonstrating that amyloid beta oligomers (A $\beta O s$ ), toxins that accumulate in brains of $\mathrm{AD}$ patients and instigate synapse damage [59], bind to hippocampal neurons and trigger the removal of insulin receptors from the plasma membrane [20, 60, 61]. Buttressing the clinical relevance of these findings, Moloney and co-workers [62] verified this phenomenon. A $\beta O$ s also alter neuronal insulin receptor function, and this effect seems to be an important aspect of the overall synaptic/ neuronal pathology induced by A $\beta O s$ [39, 60, 61].

More recently, evidence linking pathogenic mechanisms triggered by $\mathrm{A} \beta \mathrm{O}$ s in the $\mathrm{AD}$ brain to mechanisms present in metabolic diseases has emerged [39, 63, 64]. In type 2 diabetes and obesity-related insulin resistance, activation of c-Jun N-terminal kinase (JNK) leads to IRS-1 serine phosphorylation (IRS-1pSer), resulting in peripheral insulin resistance $[65,66]$. Similarly, A $\beta O$ s induce activation of the JNK pathway and IRS-1 inhibition in cultured hippocampal neurons $[39,63]$ as well as within the brain of mice and monkeys [39]. Likewise, post-mortem brains of
AD patients show abnormal distribution of IRs [62], increased serine phosphorylation of IRS-1 [10, 61] and reduced cytosolic and/or membrane levels of $\mathrm{PI} 3 \mathrm{~K}$ and PI3K-dependent kinase 1 (PDK1) [62, 67]. AD brains further display elevated levels of phosphorylated JNK [39], which is known to counteract peripheral insulin signaling [39, 68]. In conjunction, these studies suggest that the relationship between $\mathrm{CNS}$ insulin impairment and $\mathrm{A} \beta \mathrm{O}$ accumulation in the brain is rather complex and should be evaluated in future studies.

The discovery of a molecular parallel between defective brain insulin signaling in $\mathrm{AD}$ and peripheral insulin signaling dysfunction in diabetes [10, 39] provides a rationale for using anti-diabetes agents as novel therapeutics in AD. Supporting this view, a treatment with the glucagon-like peptide 1 (GLP-1) analog liraglutide (commonly used in the treatment of diabetes) leads to an amelioration of insulin resistances in the brains of $\mathrm{AD}$ patients and a mouse model of AD [69] and positive effects on neuropathology and cognition in the mouse model [70]. The next important step is to understand if and how stimulation of insulin signaling in the brain might facilitate neuroprotection, thereby preserving normal brain functioning. As touched on previously, insulin's actions seem to be important for proper hippocampal function, a region equipped with insulin receptors [71] that is profoundly involved in the acquisition, consolidation and recollection of memories.

In cell culture experiments using highly differentiated cultures of rat hippocampal neurons, the dendritic distribution of insulin receptors shows a punctate pattern, consistent with localization to synapses [20, 60]. Insulin receptor signaling further regulates synaptic plasticity by controlling synapse density [72]. In rodents, insulin receptor signaling contributes to long-term memory consolidation and improves spatial learning [73-75]. Insulin has also been proposed to regulate neuronal survival and to act as a growth factor [76], possibly by activating insulinlike growth factor (IGF) receptors [77]. An additional possible mechanism of the protective action of insulin could be the decrease in stress-induced hypothalamicpituitary-adrenal (HPA) axis activity responsiveness [78].

Interestingly, insulin also provides protection against $\mathrm{A} \beta \mathrm{O}$ s. Insulin has been found to block both $\mathrm{A} \beta \mathrm{O}$-induced reductions in insulin receptors on dendritic surfaces [20] and IRS-1pSer induced by A $\beta O$ s [39]. Remarkably, insulin protects synapses against $\mathrm{A} \beta \mathrm{O}$ s [20], and the mechanism of protection entails a decrease of $\mathrm{A} \beta \mathrm{O}$ binding sites [20]. As a consequence, insulin prevents the overall negative impact of A 30 s on neurons [20, 79]. Insulin further favors antiamyloidogenic pathways of amyloid precursor protein processing in vitro [80]. Collectively, these studies provide a rational basis for the use of insulin as an effective therapeutic agent in AD. 


\section{Intranasal Administration of Insulin: Mechanisms and Clinical Safety Issues}

Insulin has been revealed not only to control whole-body energy and glucose homeostasis in the periphery of the human body [81-84], but also to exert specific effects in the CNS. Insulin receptors have been identified in a variety of brain areas, especially in the olfactory bulb, hippocampus and hypothalamus $[57,58]$. One possible method for studying the cerebral actions of insulin is via intravenous (iv) administration. In humans, it has been shown that iv infusions of insulin are followed by increases in CSF levels of the hormone, indicating that plasma insulin accesses the brain [85]. Although iv insulin has been linked to improved memory functions in humans [86], this route of administration possesses little therapeutic potential for the treatment of CNS disorders. Intravenous application of insulin is a highly invasive technique that leads to hypoglycemia, which itself has detrimental effects on brain function and thus has to be accompanied by iv glucose infusion in order to maintain stable blood glucose levels constant in the experimental setting. Thus, this approach is not suitable for the treatment of CNS disorders. The approach of intranasal delivery of neuropeptides, however, has provided us with an alternative for the effective and rapid delivery of insulin exclusively to the brain and thereby provides the means of therapeutic use [22, 87].

Applying this method, insulin is sprayed into the nose of the subject. Following intranasal application, insulin enters the nasal mucosa and is transported extracellularly along the axon bundles of the olfactory receptor cells in the roof of the nasal cavity leading through the foramina of the lamina cribrosa to the olfactory bulb, hippocampus and other regions of the brain and upper spinal cord [21, 22, 88]. The trigeminal neural pathway has also been shown to provide a pathway from the nasal mucosa through the lamina cribrosa and the pons to the CNS [21, 89]. Another proposed transport mechanisms is via the rostral migratory stream [90].

Hence, using this intranasal delivery method, insulin directly enters the brain, bypassing the blood-brain barrier (BBB) [91], and can be detected in biologically relevant concentrations in the CSF 30-40 min following intranasal application [38]. Furthermore, these effects can be achieved with doses that do not produce changes in peripheral blood levels of insulin and glucose [22]. Thus, this method selectively increases CNS insulin levels and is therefore suitable for the investigation of both the shortand long-term effects of insulin on the human brain without the potential confound of peripheral side effects [92]. However, at this point it is important to state that an intranasal dose of $40 \mathrm{IU}$ insulin - as applied in many previous studies-results in short-term elevations of CSF insulin to $25 \mathrm{pM}$ levels, which is $4-10$ times lower than the insulin levels $(0.1-1 \mathrm{nM})$ found to trigger brain insulin signaling in postmortem brains [10]. Thus, future studies are needed to show that after intranasal insulin uptake, brain insulin levels are sufficiently raised to enhance brain insulin signaling under in vivo conditions. Nevertheless, many intranasal insulin studies have yielded effects on CNS functions in humans that resembled those found in animals after intracerebroventricular insulin administration (e.g., reduced food intake, improved spatial memory functions) $[16,18]$. That said, we believe that the current evidence is strong enough to support the view that intranasal insulin represents a promising pharmacological strategy to support insulin-sensitive CNS functions in humans.

According to the existing literature, intranasal insulin administration generally neither causes nasal irritation nor destroys the olfactory epithelium or glomerular projections [93, 94], and it therefore constitutes a clinically safe application method [95] for the dissociation of central and peripheral insulin effects.

\section{Conclusion}

Collectively, the presented studies present evidence for the hypothesis that improving central nervous insulin signaling via intranasal insulin or insulin sensitizers, which cross the blood-brain barrier, could represent an effective way to prevent or treat $\mathrm{AD}$. However, chronic insulin treatment can cause desensitization of insulin signaling pathways in peripheral tissues [95], raising concerns about the longterm efficacy of this approach. Another aspect that requires critical consideration is that earlier studies have not shown a beneficial effect of acute intranasal insulin administration in $\mathrm{AD}$ and $\mathrm{MCI}$ patients carrying at least one copy of the APOE $\varepsilon 4$ allele $[28,96]$. In the most recent 4-month clinical trial, however, positive effects of intranasally applied insulin on $\mathrm{AD}$ and $\mathrm{MCI}$ patients carrying one or two copies of the APOE\&4 allele have been shown, whereas the optimal insulin dose seems to vary between both groups [96]. Considering that the presence of one $\varepsilon 4$ allele increases the risk of developing AD two- to threefold, while having two $\varepsilon 4$ alleles increases the risk by about 15 -fold, larger studies of longer duration are needed to fully evaluate intranasal insulin's therapeutic potential in the treatment of AD.

An additional important next step for this research path is determining the mechanism of insulin's effects on cognition. This entails answering some basic questions in rodents and primates, e.g., which levels of extracellular brain insulin (as opposed to CSF insulin) are actually achieved by intranasal insulin doses that exert optimal effects on cognition? Is an increase above baseline of 
extracellular brain insulin levels sufficient to enhance brain insulin signaling or to normalize central nervous insulin signaling in the case of brain insulin resistance? Does intranasal insulin act equally with regard to neuroprotection and synaptic function? How fundamental is brain insulin resistance to the development of both familial and sporadic forms of $\mathrm{AD}$ ?

While there are many open questions regarding longitudinal efficacy and the mechanisms underlying its effect on cognition, recent clinical trials support the hypothesis that intranasal insulin may be a promising option to slow the progress of $\mathrm{AD}$ [31]. With this in mind, it is not surprising that intranasal administration of insulin in $\mathrm{AD}$ patients was recently selected by the NIH to receive substantial funding as part of the National Alzheimer's Plan in the US. In this multicenter study (recruiting has not started yet), the effects of intranasally administered insulin on cognition, entorhinal cortex, hippocampal atrophy and CSF biomarkers in amnestic MCI or mild AD will be examined in a sample of 240 people (ClinicalTrials.gov Identifier: NCT01767909). It is hypothesized that after 12 months of treatment with intranasal insulin subjects will demonstrate improved performance on a global measure of cognition, on a memory composite and in daily functioning. In addition to the examination of CSF biomarkers and hippocampal and entorhinal atrophy, the study aims to examine whether the baseline AD biomarker profile, gender or APOE- $\varepsilon 4$ allele carriage predicts treatment response.

Taken together, the findings reviewed in this article provide a strong rationale for hypothesizing that intranasal delivery of insulin or insulin sensitizers (e.g., liraglutide) represents a promising pharmacological strategy to support insulin-sensitive CNS functions in humans, including hippocampus-dependent memory formation and neuroprotection against $\mathrm{AD}$ and $\mathrm{MCI}$.

Acknowledgments Work by JF and YB is supported by START funds from the Medical Faculty of RWTH Aachen University. Work by WF has been supported by numerous pharmaceutical companies; however to the best of our knowledge, none of these companies is currently developing an intranasal insulin drug for $\mathrm{AD}$ patients. Further, WF is the listed inventor of a patent (Frey WH II. Method for administering insulin to the brain. Patent 6,313,093 B1 filed 1999 and issued November 6, 2001) related to the use of intranasal insulin. Work by WF and SC has been supported by the National Institutes of Health (NIH). SC has served as an advisory board member for Eli Lilly on one occasion to advise them regarding the design of their intranasal insulin work. Eli Lilly will also provide insulin and placebo for our multi-site intranasal insulin study at no cost and with no restrictions. Work by $\mathrm{MH}$ has been supported by the Deutsche Forschungsgemeinschaft (Sonderforschungsbereich 654-SFB 654) and by the Helmholtz Alliance (Imaging and Curing Environmental Metabolic Diseases-ICEMED). Work by FDF has been supported by grants from Human Frontiers Science Program (HFSP) and the John Simon Guggenheim Memorial Foundation, the Brazilian funding agencies Conselho Nacional de Desenvolvimento Científico e Tecnológico (CNPq), Fundação de Amparo à Pesquisa do Estado do Rio de Janeiro (FAPERJ). $\mathrm{CH}$ has been supported by the Alzheimer Research UK and Alzheimer Society UK charities. Work by CB has been supported by the Olle Engkvist Byggmästare Foundation and by the Deutsche Forschungsgemeinschaft (Sonderforschungsbereich 654-SFB 654).

The authors did not receive funding for this specific manuscript and have no conflicts of interest that are directly relevant to the content of this article.

Open Access This article is distributed under the terms of the Creative Commons Attribution Noncommercial License which permits any noncommercial use, distribution, and reproduction in any medium, provided the original author(s) and the source are credited.

\section{References}

1. Sperling RA, Aisen PS, Beckett LA, Bennett DA, Craft S, Fagan AM, et al. Toward defining the preclinical stages of Alzheimer's disease: recommendations from the National Institute on AgingAlzheimer's Association workgroups on diagnostic guidelines for Alzheimer's disease. Alzheimers Dement. 2011;7(3):280-92. doi: 10.1016/j.jalz.2011.03.003.

2. Sosa-Ortiz AL, Acosta-Castillo I, Prince MJ. Epidemiology of dementias and Alzheimer's disease. Arch Med Res. 2012;43(8): 600-8. doi:10.1016/j.arcmed.2012.11.003.

3. Alzheimer's Association. Alzheimer's disease facts and figures. 2012; http://www.alz.org.

4. 2012 Alzheimer's disease facts and figures. Alzheimers Dement. 2012;8(2):131-68. doi:10.1016/j.jalz.2012.02.001. http://www. ncbi.nlm.nih.gov/pubmed/22404854

5. Ferri CP, Prince M, Brayne C, Brodaty H, Fratiglioni L, Ganguli $\mathrm{M}$, et al. Global prevalence of dementia: a Delphi consensus study. Lancet. 2005;366(9503):2112-7. doi:10.1016/S0140-6736 (05)67889-0.

6. Holscher C, Li L. New roles for insulin-like hormones in neuronal signalling and protection: new hopes for novel treatments of Alzheimer's disease? Neurobiol Aging. 2010;31(9):1495-502. doi:10.1016/j.neurobiolaging.2008.08.023.

7. de la Monte SM. Brain insulin resistance and deficiency as therapeutic targets in Alzheimer's disease. Curr Alzheimer Res. 2012;9(1):35-66.

8. Watson GS, Craft S. The role of insulin resistance in the pathogenesis of Alzheimer's disease: implications for treatment. CNS Drugs. 2003;17(1):27-45.

9. Rivera EJ, Goldin A, Fulmer N, Tavares R, Wands JR, de la Monte SM. Insulin and insulin-like growth factor expression and function deteriorate with progression of Alzheimer's disease: link to brain reductions in acetylcholine. J Alzheimer's Dis. 2005;8(3):247-68.

10. Talbot K, Wang HY, Kazi H, Han LY, Bakshi KP, Stucky A, et al. Demonstrated brain insulin resistance in Alzheimer's disease patients is associated with IGF-1 resistance, IRS-1 dysregulation, and cognitive decline. J Clin Invest. 2012;122(4): 1316-38. doi:10.1172/JCI59903.

11. Steen E, Terry BM, Rivera EJ, Cannon JL, Neely TR, Tavares R, et al. Impaired insulin and insulin-like growth factor expression and signaling mechanisms in Alzheimer's disease-is this type 3 diabetes? J Alzheimer's Dis. 2005;7(1):63-80.

12. Craft S, Peskind E, Schwartz MW, Schellenberg GD, Raskind M, Porte D Jr. Cerebrospinal fluid and plasma insulin levels in Alzheimer's disease: relationship to severity of dementia and apolipoprotein E genotype. Neurology. 1998;50(1):164-8.

13. Molina JA, Jimenez-Jimenez FJ, Vargas C, Gomez P, de Bustos F, Gomez-Escalonilla C, et al. Cerebrospinal fluid levels of 
insulin in patients with Alzheimer's disease. Acta Neurol Scand. 2002;106(6):347-50.

14. Fujisawa Y, Sasaki K, Akiyama K. Increased insulin levels after OGTT load in peripheral blood and cerebrospinal fluid of patients with dementia of Alzheimer type. Biol Psychiatry. 1991;30(12): 1219-28.

15. Frolich L, Blum-Degen D, Bernstein HG, Engelsberger S, Humrich J, Laufer S, et al. Brain insulin and insulin receptors in aging and sporadic Alzheimer's disease. J Neural Transm. 1998;105(4-5):423-38.

16. Benedict C, Hallschmid M, Hatke A, Schultes B, Fehm HL, Born $\mathrm{J}$, et al. Intranasal insulin improves memory in humans. Psychoneuroendocrinology. 2004;29(10):1326-34. doi:10.1016/ j.psyneuen.2004.04.003S0306453004000526.

17. Benedict C, Hallschmid M, Schultes B, Born J, Kern W. Intranasal insulin to improve memory function in humans. Neuroendocrinology. 2007;86(2):136-42. doi:10.1159/000106378.

18. Benedict C, Kern W, Schultes B, Born J, Hallschmid M. Differential sensitivity of men and women to anorexigenic and memory-improving effects of intranasal insulin. J Clin Endocrinol Metab. 2008;93(4):1339-44. doi:10.1210/jc.2007-2606.

19. Holscher C. Diabetes as a risk factor for Alzheimer's disease: insulin signalling impairment in the brain as an alternative model of Alzheimer's disease. Biochem Soc Trans. 2011;39(4):891-7. doi:10.1042/BST0390891.

20. De Felice FG, Vieira MN, Bomfim TR, Decker H, Velasco PT, Lambert MP, et al. Protection of synapses against Alzheimer'slinked toxins: insulin signaling prevents the pathogenic binding of Abeta oligomers. Proc Natl Acad Sci USA. 2009;106(6): 1971-6. doi:10.1073/pnas.0809158106.

21. Thorne RG, Pronk GJ, Padmanabhan V, Frey WH 2nd. Delivery of insulin-like growth factor-I to the rat brain and spinal cord along olfactory and trigeminal pathways following intranasal administration. Neuroscience. 2004;127(2):481-96. doi:10.1016/ j.neuroscience.2004.05.029.

22. Born J, Lange T, Kern W, McGregor GP, Bickel U, Fehm HL. Sniffing neuropeptides: a transnasal approach to the human brain. Nat Neurosci. 2002;5(6):514-6. doi:10.1038/nn849.

23. Wadman M. US government sets out Alzheimer's plan. Nature. 2012;485(7399):426-7. doi:10.1038/485426a.

24. Eichenbaum $\mathrm{H}$. The hippocampus and mechanisms of declarative memory. Behav Brain Res. 1999;103(2):123-33.

25. Benedict C, Hallschmid M, Schmitz K, Schultes B, Ratter F, Fehm HL, et al. Intranasal insulin improves memory in humans: superiority of insulin aspart. Neuropsychopharmacology. 2007;32(1):239-43. doi:10.1038/sj.npp.1301193.

26. Krug R, Benedict C, Born J, Hallschmid M. Comparable sensitivity of postmenopausal and young women to the effects of intranasal insulin on food intake and working memory. J Clin Endocrinol Metab. 2010;95(12):E468-72. doi:10.1210/jc. 2010-0744.

27. Miller EK. The prefrontal cortex: complex neural properties for complex behavior. Neuron. 1999;22(1):15-7.

28. Reger MA, Watson GS, Frey WH 2nd, Baker LD, Cholerton B, Keeling ML, et al. Effects of intranasal insulin on cognition in memory-impaired older adults: modulation by APOE genotype. Neurobiol Aging. 2006;27(3):451-8. doi:10.1016/j.neurobiolaging. 2005.03.016.

29. Reger MA, Watson GS, Green PS, Baker LD, Cholerton B, Fishel $\mathrm{MA}$, et al. Intranasal insulin administration dose-dependently modulates verbal memory and plasma amyloid-beta in memoryimpaired older adults. J Alzheimer's Dis. 2008;13(3):323-31.

30. Reger MA, Watson GS, Green PS, Wilkinson CW, Baker LD, Cholerton B, et al. Intranasal insulin improves cognition and modulates beta-amyloid in early AD. Neurology. 2008;70(6): 440-8. doi:10.1212/01.WNL.0000265401.62434.36.
31. Craft S, Baker LD, Montine TJ, Minoshima S, Watson GS, Claxton A, et al. Intranasal insulin therapy for Alzheimer disease and amnestic mild cognitive impairment: a pilot clinical trial. Arch Neurol. 2012;69(1):29-38. doi:10.1001/archneurol. 2011.233.

32. Schioth HB, Frey WH, Brooks SJ, Benedict C. Insulin to treat Alzheimer's disease: just follow your nose? Expert Rev Clin Pharmacol. 2012;5(1):17-20. doi:10.1586/ecp.11.70.

33. Nickl-Jockschat T, Kleiman A, Schulz JB, Schneider F, Laird AR, Fox PT, et al. Neuroanatomic changes and their association with cognitive decline in mild cognitive impairment: a metaanalysis. Brain Struct Funct. 2012;217(1):115-25. doi:10.1007/ s00429-011-0333-x.

34. Schroeter ML, Stein T, Maslowski N, Neumann J. Neural correlates of Alzheimer's disease and mild cognitive impairment: a systematic and quantitative meta-analysis involving 1351 patients. Neuroimage. 2009;47(4):1196-206. doi:10.1016/ j.neuroimage.2009.05.037.

35. Ferreira LK, Diniz BS, Forlenza OV, Busatto GF, Zanetti MV. Neurostructural predictors of Alzheimer's disease: a meta-analysis of VBM studies. Neurobiol Aging. 2011;32(10):1733-41. doi:10.1016/j.neurobiolaging.2009.11.008.

36. Shemesh E, Rudich A, Harman-Boehm I, Cukierman-Yaffe T. Effect of intranasal insulin on cognitive function: a systematic review. J Clin Endocrinol Metab. 2012;97(2):366-76. doi:10.1210/ jc.2011-1802.

37. Benedict C, Brooks SJ, Kullberg J, Burgos J, Kempton MJ, Nordenskjold R, et al. Impaired insulin sensitivity as indexed by the HOMA score is associated with deficits in verbal fluency and temporal lobe gray matter volume in the elderly. Diabetes Care. 2012;35(3):488-94. doi:10.2337/dc11-2075.

38. Hallschmid M, Schultes B, Marshall L, Molle M, Kern W, Bredthauer J, et al. Transcortical direct current potential shift reflects immediate signaling of systemic insulin to the human brain. Diabetes. 2004;53(9):2202-8.

39. Bomfim TR, Forny-Germano L, Sathler LB, Brito-Moreira J, Houzel JC, Decker H, et al. An anti-diabetes agent protects the mouse brain from defective insulin signaling caused by Alzheimer's disease-associated Abeta oligomers. J Clin Invest. 2012;122(4):1339-53. doi:10.1172/JCI57256.

40. Correia SC, Santos RX, Perry G, Zhu X, Moreira PI, Smith MA. Insulin-resistant brain state: the culprit in sporadic Alzheimer's disease? Ageing Res Rev. 2011;10(2):264-73. doi:10.1016/j.arr. 2011.01.001.

41. Baker LD, Cross DJ, Minoshima S, Belongia D, Watson GS, Craft S. Insulin resistance and Alzheimer-like reductions in regional cerebral glucose metabolism for cognitively normal adults with prediabetes or early type 2 diabetes. Arch Neurol. 2011;68(1):51-7. doi:10.1001/archneurol.2010.225.

42. Reiman EM, Caselli RJ, Yun LS, Chen K, Bandy D, Minoshima $\mathrm{S}$, et al. Preclinical evidence of Alzheimer's disease in persons homozygous for the epsilon 4 allele for apolipoprotein E. N Engl J Med. 1996;334(12):752-8. doi:10.1056/NEJM1996032 13341202.

43. Mosconi L, Sorbi S, de Leon MJ, Li Y, Nacmias B, Myoung PS, et al. Hypometabolism exceeds atrophy in presymptomatic earlyonset familial Alzheimer's disease. J Nucl Medicine. 2006;47(11):1778-86.

44. Ohara T, Doi Y, Ninomiya T, Hirakawa Y, Hata J, Iwaki T, et al. Glucose tolerance status and risk of dementia in the community: the Hisayama study. Neurology. 2011;77(12):1126-34. doi: 10.1212/WNL.0b013e31822f0435.

45. Willette AA, Xu G, Johnson SC, Birdsill AC, Jonaitis EM, Sager MA, et al. Insulin resistance, brain atrophy, and cognitive performance in late middle-aged adults. Diabetes Care. 2012;. doi: $10.2337 / \mathrm{dc} 12-0922$. 
46. Tan ZS, Beiser AS, Fox CS, Au R, Himali JJ, Debette S, et al. Association of metabolic dysregulation with volumetric brain magnetic resonance imaging and cognitive markers of subclinical brain aging in middle-aged adults: the Framingham Offspring Study. Diabetes Care. 2011;34(8):1766-70. doi:10.2337/ dc11-0308.

47. Rasgon NL, Kenna HA, Wroolie TE, Kelley R, Silverman D, Brooks $\mathrm{J}$, et al. Insulin resistance and hippocampal volume in women at risk for Alzheimer's disease. Neurobiol Aging. 2011;32(11):1942-8. doi:10.1016/j.neurobiolaging.2009.12.005.

48. Kenna H, Hoeft F, Kelley R, Wroolie T, Demuth B, Reiss A, et al. Fasting plasma insulin and the default mode network in women at risk for Alzheimer's disease. Neurobiol Aging. 2013;34(3):641-9. doi:10.1016/j.neurobiolaging.2012.06.006.

49. Stingl KT, Kullmann S, Guthoff M, Heni M, Fritsche A, Preiss1 $\mathrm{H}$. Insulin modulation of magnetoencephalographic resting state dynamics in lean and obese subjects. Front Syst Neurosci. 2010;4:157. doi:10.3389/fnsys.2010.00157.

50. Kullmann S, Frank S, Heni M, Ketterer C, Veit R, Haring HU, et al. Intranasal insulin modulates intrinsic reward and prefrontal circuitry of the human brain in lean women. Neuroendocrinology. 2012;. doi:10.1159/000341406.

51. Grichisch Y, Cavusoglu M, Preissl H, Uludag K, Hallschmid M, Birbaumer N, et al. Differential effects of intranasal insulin and caffeine on cerebral blood flow. Human Brain Mapp. 2012;33(2):280-7. doi:10.1002/hbm.21216.

52. Guthoff M, Grichisch Y, Canova C, Tschritter O, Veit R, Hallschmid $\mathrm{M}$, et al. Insulin modulates food-related activity in the central nervous system. J Clin Endocrinol Metab. 2010;95(2):748-55. doi:10.1210/jc.2009-1677.

53. Seubert J, Freiherr J, Djordjevic J, Lundstrom JN. Statistical localization of human olfactory cortex. Neuroimage. 2012;66C: 333-42. doi:10.1016/j.neuroimage.2012.10.030.

54. Braak H, Braak E. Neuropathological stageing of Alzheimerrelated changes. Acta Neuropathol. 1991;82(4):239-59.

55. Nesterova IV, Bobkova NV, Medvinskaya NI, Samokhin AN, Aleksandrova IY. Morphofunctional state of neurons in the temporal cortex and hippocampus in relation to the level of spatial memory in rats after ablation of the olfactory bulbs. Neurosci Behav Physiol. 2008;38(4):349-53. doi:10.1007/ s11055-008-0048-5.

56. Hawkes C. Olfaction in neurodegenerative disorder. Adv Otorhinolaryngol. 2006;63:133-51. doi:10.1159/000093759.

57. Zhao WQ, Alkon DL. Role of insulin and insulin receptor in learning and memory. Mol Cell Endocrinol. 2001;177(1-2): $125-34$.

58. Unger JW, Livingston JN, Moss AM. Insulin receptors in the central nervous system: localization, signalling mechanisms and functional aspects. Prog Neurobiol. 1991;36(5):343-62.

59. Ferreira ST, Klein WL. The A $\beta$ oligomer hypothesis for synapse failure and memory loss in Alzheimer's disease. Neurobiol Learn Mem. 2011;96(4):529-43. doi:10.1016/j.nlm.2011.08.003.

60. Zhao WQ, De Felice FG, Fernandez S, Chen H, Lambert MP, Quon MJ, et al. Amyloid beta oligomers induce impairment of neuronal insulin receptors. FASEB J. 2008;22(1):246-60.

61. De Felice FG. Alzheimer's disease and insulin resistance: translating basic science into clinical applications. J Clin Invest. 2013;123(2):531-9. doi:10.1172/JCI64595.

62. Moloney AM, Griffin RJ, Timmons S, O'Connor R, Ravid R, O'Neill C. Defects in IGF-1 receptor, insulin receptor and IRS-1/ 2 in Alzheimer's disease indicate possible resistance to IGF-1 and insulin signalling. Neurobiol Aging. 2010;31(2):224-43. doi: 10.1016/j.neurobiolaging.2008.04.002.

63. Ma QL, Yang F, Rosario ER, Ubeda OJ, Beech W, Gant DJ, et al. $\beta$-amyloid oligomers induce phosphorylation of tau and inactivation of insulin receptor substrate via c-Jun $\mathrm{N}$-terminal kinase signaling: suppression by omega-3 fatty acids and curcumin. J Neurosci. 2009;29(28):9078-89. doi:10.1523/jneurosci.107109.2009.

64. Craft S. Alzheimer disease: insulin resistance and AD-extending the translational path. Nat Rev Neurol. 2012;8(7):360-2. doi: 10.1038/nrneurol.2012.112.

65. Hirosumi J, Tuncman G, Chang L, Gorgun CZ, Uysal KT, Maeda $\mathrm{K}$, et al. A central role for JNK in obesity and insulin resistance. Nature. 2002;420(11):333-6.

66. Vallerie SN, Hotamisligil GS. The role of JNK proteins in metabolism. Science Transl Med. 2010;2:60rv5.

67. Liu Y, Liu F, Grundke-Iqbal I, Iqbal K, Gong CX. Deficient brain insulin signalling pathway in Alzheimer's disease and diabetes. J Pathol. 2011;225(1):54-62. doi:10.1002/path.2912.

68. Hirosumi J, Tuncman G, Chang L, Gorgun CZ, Uysal KT, Maeda $\mathrm{K}$, et al. A central role for JNK in obesity and insulin resistance. Nature. 2002;420(6913):333-6. doi:10.1038/nature01137.

69. Wang H-Y, editor. The diabetes drug liraglutide ameliorates insulin resistance in the hippocampal formation of Alzheimer's disease (AD) cases. 2011 Neuroscience Meeting Planner; 2011; Washington, DC: Society for Neuroscience.

70. McClean PL, Parthsarathy V, Faivre E, Holscher C. The diabetes drug liraglutide prevents degenerative processes in a mouse model of Alzheimer's disease. J Neurosci. 2011;31(17):6587-94. doi:10.1523/JNEUROSCI.0529-11.2011.

71. Zhao WQ, Alkon DL. Role of insulin and insulin receptor in learning and memory. Mol Cell Endocrinol. 2001;177:125-34.

72. Chiu S-L, Chen C-M, Cline HT. Insulin receptor signaling regulates synapse number, dendritic plasticity, and circuit function in vivo. Neuron. 2008;58(5):708-19. doi:10.1016/j.neuron. 2008.04.014.

73. Zhao WQ, Chen H, Quon MJ, Alkon DL. Insulin and the insulin receptor in experimental models of learning and memory. Eur J Pharmacol. 2004;490(1-3):71-81. doi:10.1016/j.ejphar.2004.02. 045.

74. Haj-ali V, Mohaddes G, Babri SH. Intracerebroventricular insulin improves spatial learning and memory in male Wistar rats. Behav Neurosci. 2009;123(6):1309-14. doi:10.1037/a0017722.

75. Francis GJ, Martinez JA, Liu WQ, Xu K, Ayer A, Fine J, et al. Intranasal insulin prevents cognitive decline, cerebral atrophy and white matter changes in murine type I diabetic encephalopathy. Brain. 2008;131(12):3311-34. doi:10.1093/brain/awn288.

76. Li L, Hölscher C. Common pathological processes in Alzheimer disease and type 2 diabetes: a review. Brain Res Rev. 2007;56(2):384-402. doi:10.1016/j.brainresrev.2007.09.001.

77. Fernandez AM, Torres-Alemán I. The many faces of insulin-like peptide signalling in the brain. Nat Rev Neurosci. 2012;13(4): 225-39. doi:10.1038/nrn3209.

78. Bohringer A, Schwabe L, Richter S, Schachinger H. Intranasal insulin attenuates the hypothalamic-pituitary-adrenal axis response to psychosocial stress. Psychoneuroendocrinology. 2008;33(10):1394-400. doi:10.1016/j.psyneuen.2008.08.002.

79. Townsend M, Mehta T, Selkoe DJ. Soluble Abeta inhibits specific signal transduction cascades common to the insulin receptor pathway. J Biol Chem. 2007;282:33305-12.

80. Pandini G, Pace V, Copani A, Squatrito S, Milardi D, Vigneri R. Insulin has multiple antiamyloidogenic effects on human neuronal cells. Endocrinology. 2012;154(1):375-87. doi:10.1210/en. 2012-1661.

81. Hallschmid M, Higgs S, Thienel M, Ott V, Lehnert H. Postprandial administration of intranasal insulin intensifies satiety and reduces intake of palatable snacks in women. Diabetes. 2012;61(4):782-9. doi:10.2337/db11-1390.

82. Hallschmid M, Benedict C, Schultes B, Fehm HL, Born J, Kern $\mathrm{W}$. Intranasal insulin reduces body fat in men but not in women. Diabetes. 2004;53(11):3024-9. 
83. Benedict C, Brede S, Schioth HB, Lehnert H, Schultes B, Born J, et al. Intranasal insulin enhances postprandial thermogenesis and lowers postprandial serum insulin levels in healthy men. Diabetes. 2011;60(1):114-8. doi:10.2337/db10-0329.

84. Ott V, Benedict C, Schultes B, Born J, Hallschmid M. Intranasal administration of insulin to the brain impacts cognitive function and peripheral metabolism. Diabetes Obes Metab. 2012;14(3): 214-21. doi:10.1111/j.1463-1326.2011.01490.x.

85. Wallum BJ, Taborsky GJ Jr, Porte D Jr, Figlewicz DP, Jacobson $\mathrm{L}$, Beard JC, et al. Cerebrospinal fluid insulin levels increase during intravenous insulin infusions in man. J Clin Endocrinol Metab. 1987;64(1):190-4.

86. Kern W, Peters A, Fruehwald-Schultes B, Deininger E, Born J, Fehm HL. Improving influence of insulin on cognitive functions in humans. Neuroendocrinology. 2001;74(4):270-80. doi:54694.

87. Hanson LR, Frey WH 2nd. Intranasal delivery bypasses the blood-brain barrier to target therapeutic agents to the central nervous system and treat neurodegenerative disease. BMC Neurosci. 2008;9(Suppl 3):S5. doi:10.1186/1471-2202-9-S3-S5.

88. Thorne RG, Emory CR, Ala TA, Frey WH 2nd. Quantitative analysis of the olfactory pathway for drug delivery to the brain. Brain Res. 1995;692(1-2):278-82. doi:10.1016/0006-8993(95) 00637-6.

89. Lochhead JJ, Thorne RG. Intranasal delivery of biologics to the central nervous system. Adv Drug Deliv Rev. 2012;64(7): 614-28. doi:10.1016/j.addr.2011.11.002.

90. Chapman CD, Frey WH 2nd, Craft S, Danielyan L, Hallschmid $\mathrm{M}$, Schioth $\mathrm{HB}$, et al. Intranasal treatment of central nervous system dysfunction in humans. Pharm Res. 2012. doi: 10.1007/s11095-012-0915-1.

91. Baura GD, Foster DM, Porte D Jr, Kahn SE, Bergman RN, Cobelli $\mathrm{C}$, et al. Saturable transport of insulin from plasma into the central nervous system of dogs in vivo. A mechanism for regulated insulin delivery to the brain. $\mathrm{J}$ Clin Invest. 1993;92(4):1824-30. doi:10.1172/JCI116773.

92. Renner DB, Svitak AL, Gallus NJ, Ericson ME, Frey WH 2nd, Hanson LR. Intranasal delivery of insulin via the olfactory nerve pathway. J Pharm Pharmacol. 2012;64(12):1709-14. doi: 10.1111/j.2042-7158.2012.01555.x.

93. Marks DR, Tucker K, Cavallin MA, Mast TG, Fadool DA. Awake intranasal insulin delivery modifies protein complexes and alters memory, anxiety, and olfactory behaviors. J Neurosci. 2009;29(20):6734-51. doi:10.1523/JNEUROSCI.1350-09.2009.

94. Khafagy el-S, Morishita M, Onuki Y, Takayama K. Current challenges in non-invasive insulin delivery systems: a comparative review. Adv Drug Deliv Rev. 2007;59(15):1521-46. doi: 10.1016/j.addr.2007.08.019.

95. Kupila A, Sipila J, Keskinen P, Simell T, Knip M, Pulkki K, et al. Intranasally administered insulin intended for prevention of type 1 diabetes-a safety study in healthy adults. Diabetes Metab Res Rev. 2003;19(5):415-20. doi:10.1002/dmrr.397.

96. Claxton A, Baker LD, Wilkinson CW, Trittschuh EH, Chapman D, Watson GS, et al. Sex and ApoE genotype differences in treatment response to two doses of intranasal insulin in adults with mild cognitive impairment or Alzheimer's disease. J Alzheimer's Dis. 2013. doi:10.3233/JAD-122308. 